\title{
Oxidized Low Density Lipoprotein (OX-LDL) Induced Arterial Muscle Contraction Signaling Mechanisms
}

\author{
C. Subah Packer ${ }^{1, *}$, Ami E. Rice ${ }^{1}$, Tomalyn C. Johnson ${ }^{1}$, Nancy J. Pelaez ${ }^{4}$, Constance J. Temm ${ }^{2}$, \\ George V. Potter ${ }^{1}$, William A. White ${ }^{1}$, Alan H. Roth ${ }^{1}$, Jesus H. Dominguez ${ }^{2}$ and \\ Richard G. Peterson ${ }^{3,5}$
}

\author{
${ }^{I}$ Departments of Cellular \& Integrative Physiology, ${ }^{2}$ Medicine (Nephrology) and ${ }^{3}$ Anatomy \& Cell Biology, Indiana \\ University School of Medicine, Indianapolis, Indiana 46202; ${ }^{4}$ Department of Biological Sciences, Purdue University, \\ and ${ }^{5}$ PreClinOmics (PCO), Inc., USA
}

\begin{abstract}
Oxidized low-density lipoprotein cholesterol (OX-LDL), a reactive oxidant, forms when reactive oxygen species interact with LDL. Elevated OX-LDL may contribute to high blood pressure associated with diseases such as diabetes and obesity. The current study objective was to determine if OX-LDL is a vasoconstrictor acting through the OX-LDL receptor (LOX1) on arterial smooth muscle and elucidate the intracellular signaling mechanism. Arteries were extracted from Sprague-Dawley rats (SD) and obese $\mathrm{F}_{1}$ offspring (ZS) of Zucker diabetic fatty rats (ZDF) x spontaneously hypertensive heart failure rats (SHHF). Pulmonary arterial and aortic rings and caudal arterial helical strips were attached to force transducers in muscle baths. Arterial preparations were contracted with high $\mathrm{KCl}$ to establish maximum force development in response to membrane depolarization $\left(\mathrm{P}_{\mathrm{o}}\right)$. Addition of OX-LDL caused contractions of varying strength dependent on the arterial type. OX-LDL contractions were normalized to $\% \mathrm{P}_{\mathrm{o}}$. Caudal artery was more reactive to OX-LDL than aorta or pulmonary artery. Interestingly, LOX1 density varied with arterial type in proportion to the magnitude of the contractile response to OX-LDL. OX-LDL contractions in the absence of calcium generated about $50 \%$ as much force as in normal calcium. Experiments with myosin light chain kinase and Rho kinase inhibitors, ML-9 and Y-27632, suggest OX-LDL induced contraction is mediated by additive effects of two distinct signaling pathways activated concomitantly in the presence of calcium. Results may impact development of new therapeutic agents to control hypertension associated with disorders in which circulating LDL levels are high in a high oxidizing environment.
\end{abstract}

Keywords: Arterial smooth muscle, calcium-independent contraction, diabetes, hypertension, oxidized-LDL, vasoactive oxidants.

\section{INTRODUCTION}

Reactive oxygen species (ROS) are produced throughout the body both intracellularly and extracellularly. Of particular interest are ROS in the circulation which have been shown to be vasoactive agonists and can potentially alter vascular resistance. For example, $\mathrm{H}_{2} \mathrm{O}_{2}$ has been shown to be a direct vasoconstrictor $[1,2]$. Highly saturated fat diets and/or metabolic disorders can result in abnormally high levels of LDL, an important constituent of stenotic atherosclerotic plaques that impede blood flow [3]. LDL may play another role in cardiovascular disease through its conversion to oxidized LDL [4]. Oxidized low-density lipoprotein cholesterol (OX-LDL) can increase substantially in hypercholesterolemia, non-insulin dependent (Type II) diabetes mellitus (NIDDM) and obesity. Elevated OX-LDL levels may play a causative role in the hypertension that is associated with all of these disorders. OX-LDL may be a direct vascular smooth muscle contractile agent like $\mathrm{H}_{2} \mathrm{O}_{2}[1,2]$ with abnormally high levels causing increased resistance resulting in high

*Address correspondence to this author at the PreClinOmics (PCO), 7918 Zionsville Road, Indianapolis, IN 46268, USA;

Tel: 317-872-6001; Fax: 317-872-6002;

E-mail: cspacker@preclinomics.com blood pressure. This may be particularly relevant in cases of metabolic syndrome and Type II diabetes where LDL levels are elevated in a high oxidizing environment due to hyperglycemia.

The cellular signal transduction pathway of ROS induced contraction is not known. $\mathrm{H}_{2} \mathrm{O}_{2}$ causes smooth muscle contraction by a signaling pathway that is independent of calcium and of myosin phosphorylation [2]. Both $\mathrm{H}_{2} \mathrm{O}_{2}$ and OX-LDL may very well cause contraction by a common mechanism. On the other hand, OX-LDL is a slightly electronegatively charged molecule [5]. The negative charge may reverse the electrical gradient and open voltage-gated L-type calcium channels. Consequent calcium influx may contribute to the onset of smooth muscle contraction. Therefore, the purpose of the current study was to determine if OX-LDL is a direct vasoconstrictor acting via activation of the OX-LDL receptor (LOX1) and whether OX-LDL induced arterial smooth muscle contraction is calcium and myosin light chain kinase or rho kinase dependent.

\section{METHODS}

Oxidation of LDL (Sigma-Aldrich Chemicals) was catalyzed with copper sulfate. Vials of human LDL (Sigma \# 
L-2139), containing ethylenediaminetetraacetic acid (EDTA) as a preservative to chelate metal ions and prevent natural oxidation, were incubated with $10 \mu \mathrm{l}$ of $0.01 \mathrm{M}$ $\mathrm{CuSO}_{4} / 5 \mathrm{mg} / \mathrm{ml} \mathrm{LDL}$ at $37^{\circ} \mathrm{C}$ in the dark and open to room air for twenty-four hours with overnight dialysis against a $0.15 \mathrm{M} \mathrm{NaCl}$ solution to remove $\mathrm{CuSO}_{4}$ from the oxidized LDL solution. After the 24-hour incubation period, thiobarbituric acid-reactive substances (TBARS) were measured on randomly selected vials to confirm oxidation of the LDL. A blank, a control and a test sample were prepared as follows: The blank was composed of $2 \mathrm{ml} \mathrm{15 \%}$ thiobarbituric acid (TBA)-37.5\% trichloroacetic acid (TCA)- $0.25 \mathrm{~N} \mathrm{HCl}$. The test sample contained $1 \mathrm{ml}$ of OX-LDL along with $2 \mathrm{ml}$ of $15 \%$ TBA-37.5\% TCA- $0.25 \mathrm{~N} \mathrm{HCl}$. The control contained $1 \mathrm{ml}$ of LDL and $2 \mathrm{ml}$ of $15 \%$ TBA-37.5\% TCA- $0.25 \mathrm{~N}$ $\mathrm{HCl}$. The three samples were heated for 15 minutes in a beaker of boiling water. After heating, the samples were cooled and centrifuged for ten minutes at $1000 \mathrm{~g}$ to remove precipitate. Absorbance of the supernatant was measured at a wavelength of $535 \mathrm{~nm}$ in a spectrophotometer. Beer's law $(\mathrm{Fc}=\mathrm{FA} / \mathrm{Fa}$, where $\mathrm{Fc}$ is the concentration, $\mathrm{FA}$ is the absorbency and $\mathrm{Fa}$ is the molar absolutivity which is unique to each substance and is $1.56 \times 105$ for LDL) was used to calculate the concentrations of LDL and OX-LDL. The concentration was then used in another formula to find the level of oxidation as follows: $\mathrm{FL}=\mathrm{F} 1 / \mathrm{F} 2$, where $\mathrm{F} 1$ is the concentration of oxidized LDL following $24 \mathrm{~h}$ of exposure to $\mathrm{CuSO}_{4} /$ air and F2 is the concentration of the LDL prior to exposure to high oxidizing conditions.

Adult Sprague-Dawley rats (S-D) were sacrificed by $\mathrm{CO}_{2}$ inhalation followed by decapitation to ensure death. Caudal arteries were excised and placed in ice-cold Krebs-Henseleit buffer solution (KHB: $115 \mathrm{mM} \mathrm{NaCl}, 25 \mathrm{mM} \mathrm{NaHCO}$, $1.38 \mathrm{mM} \mathrm{NaH}{ }_{2} \mathrm{PO}_{4}, 2.51 \mathrm{mM} \mathrm{KCl}, 2.46 \mathrm{mM} \mathrm{MgSO}$, $1.91 \mathrm{mM} \mathrm{CaCl}_{2}$, and $5.56 \mathrm{mM}$ Dextrose). The excised artery was slid onto a surgical steel spoke about $500 \mu \mathrm{m}$ in diameter in a bath of cold KHB and cut open helically at an angle of $20^{\circ}$ from the transverse axis. Helical strips of one centimeter in length and $0.5-1.0 \mathrm{~mm}$ in width were mounted vertically in muscle baths. One end of each strip was attached via low compliance 7.0 surgical silk thread to a stationary surgical steel hook in the lower end of the bath. The other end was attached by a 7.0 silk ligature to a piano wire connected to a force transducer (Grass model FT 03C). The baths were filled with KHB that was bubbled with a $95 \%$ $\mathrm{O}_{2} / 5 \% \mathrm{CO}_{2}$ gas mixture and maintained at $37^{\circ} \mathrm{C}$ by a circulating outer jacket. Once mounted, muscle strips were allowed to equilibrate for about one hour prior to conducting the experiment. A series of maximum $\mathrm{KCl}(120 \mathrm{mM})$ induced contractions were used to adjust the resting length to the optimal length $\left(1_{0}\right)$ for maximum active force generation for each strip. Once $1_{0}$ was attained, a $120 \mathrm{mM} \mathrm{KCl}$ contraction was elicited to determine the maximum force generated in response to membrane depolarization $\left(\mathrm{P}_{\mathrm{o}}\right)$.

Proteins foam in aerated media and data recorded from force transducers can be masked by noise created by foaming. The current study tested the effect of Antifoam A, a silicone based polymer in a $30 \%$ aqueous emulsion containing non-ionic emulsifiers R:36 S:26-36 (Sigma A-5758), on vascular muscle contractile function as a candidate non-toxic antifoaming agent. Following the one-hour equilibration period, maximum force production in response to $120 \mathrm{mM}$
$\mathrm{KCl}\left(\mathrm{P}_{\mathrm{o}}\right)$ was established. $\mathrm{KCl}$ was washed out and the muscle relaxed. $\mathrm{H}_{2} \mathrm{O}_{2}(3 \mathrm{mM})$ was added alone or concurrently with Antifoam A. The effect of Antifoam A on the response to $120 \mathrm{mM} \mathrm{KCl}$ was also measured. Data were normalized to $\mathrm{P}_{\mathrm{o}}$. Antifoam A was inert, in that it had no effects on the muscle, and specifically did not affect resting tension nor contractile responses to $\mathrm{KCl}$ or $\mathrm{H}_{2} \mathrm{O}_{2}$.

In another series of experiments, male $\mathrm{ZS}$ rats $\left(\mathrm{F}_{1}\right.$ progeny from Zucker diabetic fatty rats crossed with spontaneously hypertensive heart failure rats; Genetic Models, Inc) were sacrificed as indicated above and then caudal and pulmonary arteries and abdominal aortae were excised. Caudal arteries were cut into helical strips and mounted in muscle baths as described above. Pulmonary arteries and aortae were cut into rings (1.0-1.5 $\mathrm{mm}$ in diameter and $2.5-4.0 \mathrm{~mm}$ in length) and mounted on two fine wires (300 $\mu \mathrm{m}$ in diameter) attached to force transducers (Grass) in muscle baths. Following equilibration at optimal resting tension, the preparations were stimulated supramaximally with $\mathrm{KCl}$ to generate maximal active force $\left(\mathrm{P}_{\mathrm{o}}\right)$. After washout and complete relaxation, $200 \mu \mathrm{g} / \mu \mathrm{l}$ (a high physiological dose) OX-LDL was added to each bath. In control experiments, LDL instead of OX-LDL was added to the muscle bath. At the end of each experiment, the tissue was blotted and weighed so that data could be normalized to tissue cross sectional area (CSA). Results are expressed as $\% \mathrm{P}_{\mathrm{o}}$ or as force per unit CSA and mean maximum responses were compared.

Adjacent ZS arterial segments were cleaned of adhering fat and connective tissue and fixed in $4 \%$ paraformaldehyde (PFA). Fixed tissues were frozen and cut into $7 \mu \mathrm{m}$ thick sections using a cryotome. OX-LDL receptor (LOX1) polyclonal antibody (raised in rabbits against recombinant rat LOX1) was added to prepared slides (1:100 Ab to PBS- $0.5 \%$ BSA dilution) and incubated for 1 hour at $20^{\circ} \mathrm{C}$ in a humidifier box in the dark. After washing twice with PBS and tapping dry, several stains were added in order to identify LOX1 on smooth muscle and on other cell types in the tissue: Secondary Ab was Alexa Fluor 568 goat-anti-rabbit (1:200 Ab to PBS-0.5\% BSA dilution, $1 \mathrm{hr}$; Molecular Probes); Alexa FL-488 conjugated phalloidin (Molecular Probes) to stain filamentous actin (1:100 PBS-0.5\%BSA dilution); DAPI (Sigma), a nuclear material fluorescent stain (1:100 PBS-0.5\%BSA dilution). Stained sections were again incubated for 1 hour at $20^{\circ} \mathrm{C}$ in a humidifier box in the dark but then rinsed with distilled $\mathrm{H}_{2} \mathrm{O}$ and tapped dry. Cover slips were sealed with mounting media containing antibleaching agent (Vectorshield) to preserve fluorescent stains and tissues. Immunofluorescence was evaluated using a confocal microscope (Zeis LSM 510) with an UV laser (Enterprise). The krypton/argon laser for green fluorescence $(488 \mathrm{~nm})$ was set to $30 \%$ intensity. The helium/neon laser for red fluorescence $(543 \mathrm{~nm})$ and the UV laser $(364 \mathrm{~nm})$ were used at $100 \%$ intensity. Gains and offsets were kept constant for every sample group. Using a focus motor, 50-75 optical sections were made at $1 \mu \mathrm{m}$ intervals. The amount of red $(568 \mathrm{~nm})$ stain indicating LOX1 expression was quantified with Metamorph software (Universal Imaging).

In other experiments, caudal arterial muscle strips from $\mathrm{S}-\mathrm{D}$ were equilibrated and $\mathrm{P}_{\mathrm{o}}$ was established as described above. Then one bath was maintained in normal calcium KHB while another bath was switched to zero calcium KHB 
(115 mM NaCl, $25 \mathrm{mM} \mathrm{NaHCO}, 1.38 \mathrm{mM} \mathrm{NaH}_{2} \mathrm{PO}_{4}$, $2.51 \mathrm{mM} \mathrm{KCl}, 2.46 \mathrm{mM} \mathrm{MgSO} 4,0.1 \mathrm{mM}$ EGTA and $5.56 \mathrm{mM}$ Dextrose). A series of consecutive $120 \mathrm{mM} \mathrm{KCl}$ stimulations and washouts ensured that the calcium stores were depleted in the muscle in the zero calcium KHB. Then $5 \mu \mathrm{l}$ of Antifoam A was added to both the normal calcium and the zero calcium baths to prevent foaming upon addition of OX-LDL. The MLCK inhibitor, ML-9 $(200 \mu \mathrm{M})$, and the Rho kinase inhibitor, Y-27632 $(10 \mu \mathrm{M})$ were added either independently or in combination to the baths. OX-LDL $(200 \mu \mathrm{M})$ was then added to each bath. Responses to OX-LDL were normalized to $\% \mathrm{P}_{\mathrm{o}}$ for comparative purposes. In a final series of experiments, S-D caudal arterial muscle strips were exposed to LOX1 polyclonal antibody (raised in rabbits against recombinant rat LOX1) in a 1/100 dilution (20 $\mu \mathrm{l} / 20 \mathrm{ml}$ bath) 20 minutes prior to addition of OX-LDL.

Results are presented as mean +/- SEM. Statistically significant differences were established when $\mathrm{p}<0.05$ with unpaired Student's t-test for any two mean values and with One Way ANOVA followed by Newman-Keul's test when comparing multiple means.

\section{RESULTS}

$\mathrm{CuSO}_{4}$ was a more powerful oxidant of LDL than exposure to air alone over a 24 hour period as shown in (Fig. 1). Antifoam A, alone, had no effect on the resting muscle nor did it affect contractile responses to $\mathrm{KCl}$ or $\mathrm{H}_{2} \mathrm{O}_{2}$ (Fig. 2). Therefore, Antifoam A was determined to be a physiologically inert tool useful for improving quality of data generated when muscle bath foaming poses a problem such as when protein agonists are investigated.

Arterial muscle contracted directly in response to oxidized-LDL (Fig. 3). Although the OX-LDL induced contraction was fairly rigorous for caudal arterial muscle (Figs. 3 and 4), pulmonary arterial muscle and aortic muscle contracted negligibly to OX-LDL (Fig. 4). No significant contraction was generated in response to untreated LDL in any of the three vascular muscles investigated.
Responsiveness of each arterial muscle type to OX-LDL stimulation correlates with LOX1 receptor density as seen by comparing confocal microscopy images of caudal arterial, aortic and pulmonary arterial sections labeled with LOX1 antibody (Fig. 5). LOX1, is present on all arterial smooth muscle regardless of arterial type, but the media of the small muscular caudal artery has a higher density of LOX1than does the media of the larger conduit abdominal aorta or the low pressure pulmonary artery.

OX-LDL contraction can occur in the absence of calcium as shown in (Fig. 6). However, the full magnitude of the contractile response to OX-LDL is not attained in calcium-free solution. The calcium-independent component of the OX-LDL contraction suggested that the OX-LDL response could also be independent of myosin light chain kinase (MLCK) activity. A signaling cascade known to mediate calcium-independent smooth muscle contraction such as the postulated Rho pathway could be operating. The MLCK inhibitor, ML-9, had a significant inhibitory effect reducing OX-LDL contractile force by about $66 \%$, while the Rho kinase inhibitor, Y-27632, caused approximately $43 \%$ reduction of the OX-LDL contraction as shown in (Fig. 7). Used in combination, the effects of the two kinase inhibitors appears to be additive, reducing the OX-LDL contraction by $90 \%$. These results suggest that OX-LDL contraction may be due to the summative effect of the two distinct kinase cascade signaling pathways that have been concomitantly (simultaneously or sequentially) activated in the presence of calcium.

\section{DISCUSSION}

Vascular production of reactive oxygen species including the superoxide anion, hydrogen peroxide $\left(\mathrm{H}_{2} \mathrm{O}_{2}\right)$ and the highly reactive hydroxyl free radical increase substantially in hypertension [6-8]. Normally, the superoxide anion is shortlived as it is rapidly converted to more stable hydrogen peroxide by the enzyme superoxide dismutase (SOD). The idea that oxidants such as hydrogen peroxide may be

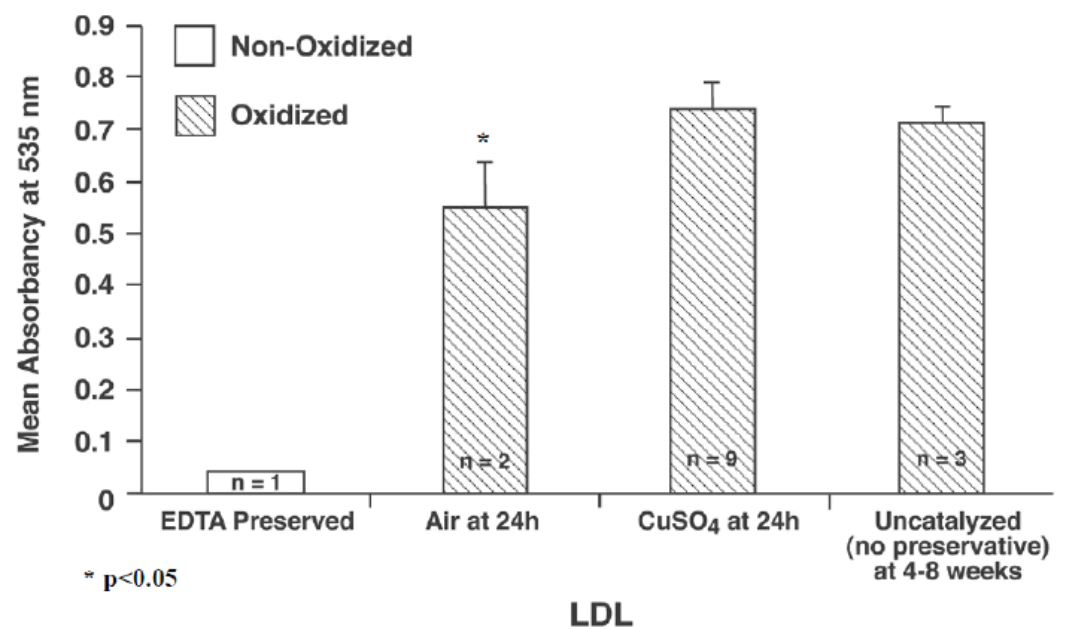

Fig. (1). Bar graph comparing levels of oxidation of LDL under different conditions. EDTA prevented significant oxidation of LDL ( $\mathrm{n}=1$ ). $\mathrm{CuSO}_{4}$ exposure $(\mathrm{n}=9)$ produced greater oxidation over a 24 hour incubation period compared with air oxidation over the same period of time $(n=2 ; p<0.05)$. In the absence of a catalyst, $(n=3)$, oxidation occurred slowly but by 8 weeks reaches similar levels to that catalyzed by $\mathrm{CuSO}_{4}$ for 24 hours. 


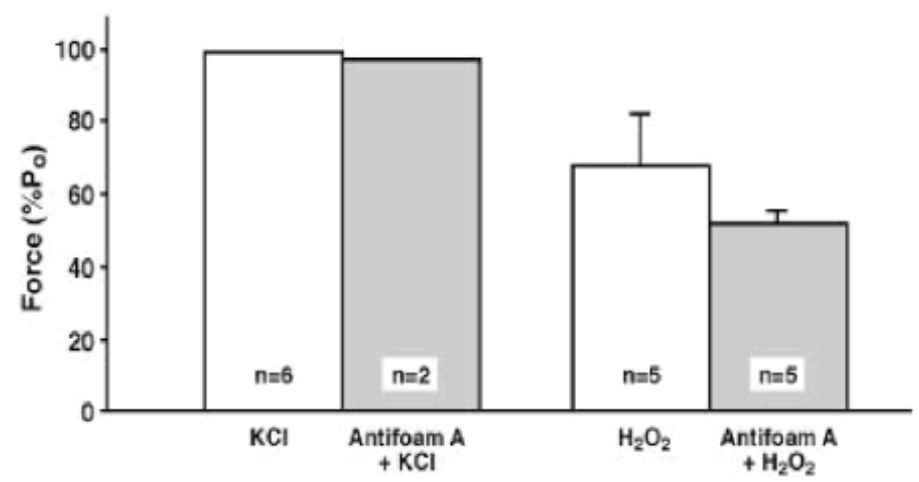

Fig. (2). Bar graphs comparing mean rat caudal arterial muscle contractile responses to $120 \mathrm{mM} \mathrm{KCl}$ and to $3 \mathrm{mM} \mathrm{H}_{2} \mathrm{O}_{2}$. Antifoam A had no effect on the response to $\mathrm{KCl}$ or to $\mathrm{H}_{2} \mathrm{O}_{2}(\mathrm{p}>0.05)$.
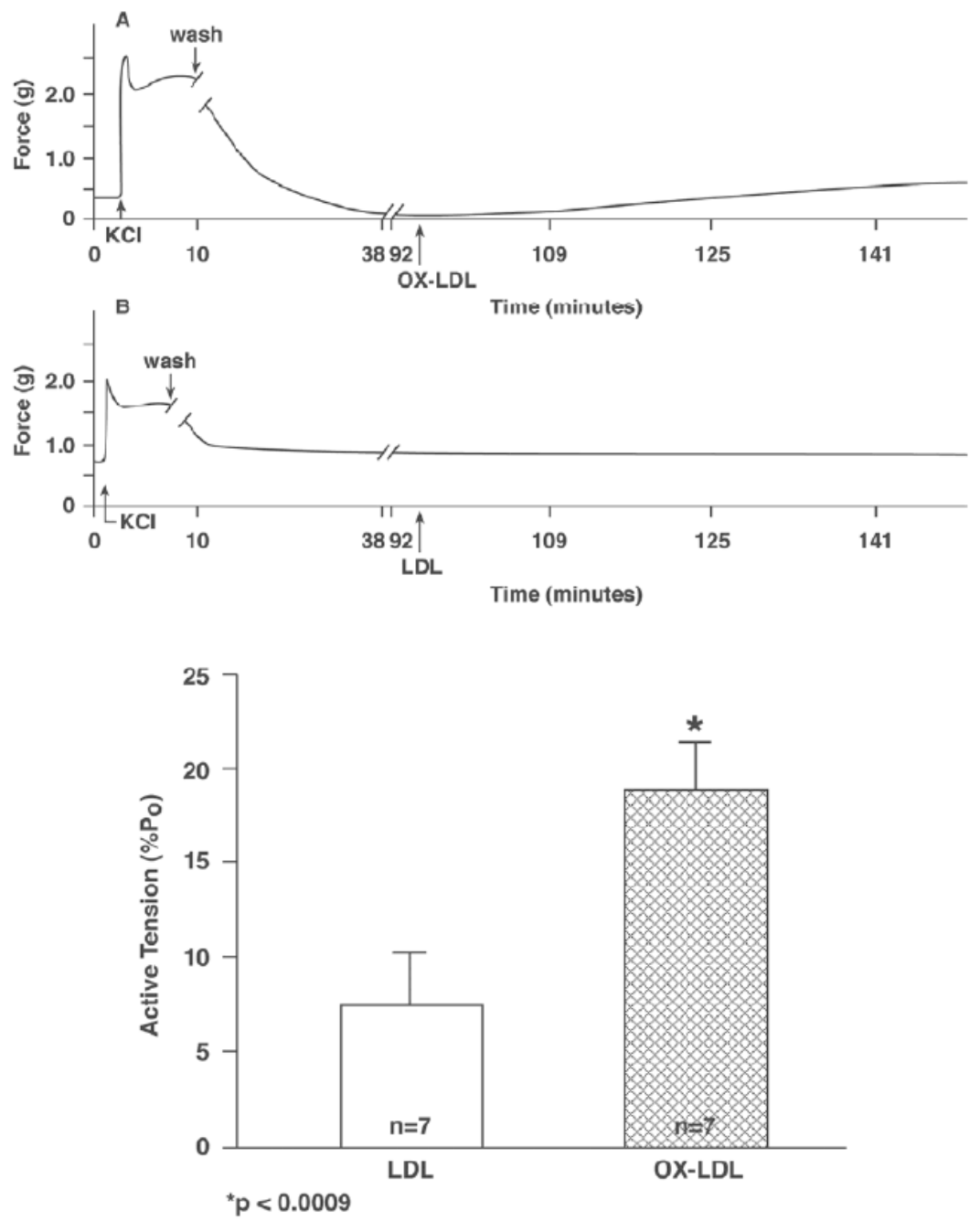

Fig. (3). Upper Panel: Typical isometric Force vs Time tracings for ZS rat caudal arterial muscle strips in response to high $\mathrm{K}^{+}$and to $\mathrm{OX}-\mathrm{LDL}$ or LDL. Following an equilibration period at optimal resting tension, the strips were maximally contracted with a supramaximal high $\mathrm{K}^{+}$ stimulus. The muscle relaxed completely after washout of the $\mathrm{KCl}$. Then, either OX-LDL or LDL was added. OX-LDL resulted in a gradually developed contraction (A), while LDL had little or no affect (B). Lower Panel: Bar graph comparing mean active isometric tension (\% $\mathrm{P}_{\mathrm{o}}$ ) developed by caudal arterial muscle from ZS male rats in response to $200 \mu \mathrm{g} / \mathrm{ml} \mathrm{LDL}$ and to $200 \mu \mathrm{g} / \mathrm{ml}$ OX-LDL. OX-LDL resulted in significant active tension development while the response to LDL was negligible $(\mathrm{p}<0.0009)$.

physiological signals was introduced in 1989 [9] and has gained support but remains controversial [10-13]. However, recent developments emphasize that it is important to look at the role of oxidants on hypertension. Jameson et al. [14] found an increased production of a "contractile factor" thought to be superoxide anions in young spontaneously hypertensive rats (SHR) even before the development of overt hypertension. Vascular smooth muscle cells were 
shown to release oxidants in response to angiotensin II stimulation and catalase cell loading inhibited this response to angiotensin II [13]. Increasing SOD raised blood pressure by $50 \mathrm{mmHg}$ in a model of angiotensin II-induced hypertension [15], implicating a role for hydrogen peroxide in hypertension. Other studies have shown that hydrogen peroxide directly causes smooth muscle contraction [16-18]. Hydrogen peroxide levels within the concentration range shown to cause contraction in vitro, have been detected in people under normal physiological as well as pathophysiological conditions [15, 19-21]. Oxidants such as $\mathrm{H}_{2} \mathrm{O}_{2}$ have also been reported to induce a slow, sustained, endotheliumindependent contraction in vascular smooth muscle [16] that is independent of the $\mathrm{Ca}^{2+}-\mathrm{MLC}_{20}$ phosphorylationdependent signal transduction pathway $[14,18]$. Perhaps of even greater clinical interest given the explosive growth in incidence of metabolic syndrome, Type II diabetes and hypercholesterolemia, is the fact that OX-LDL causes direct, receptor-mediated contraction of rat vascular smooth muscle as shown in the current study. Oxidized-LDL stimulation of vascular muscle could be a major contributing factor in the development of hypertension especially in disorders associated with high oxidizing environments such as in metabolic syndrome.

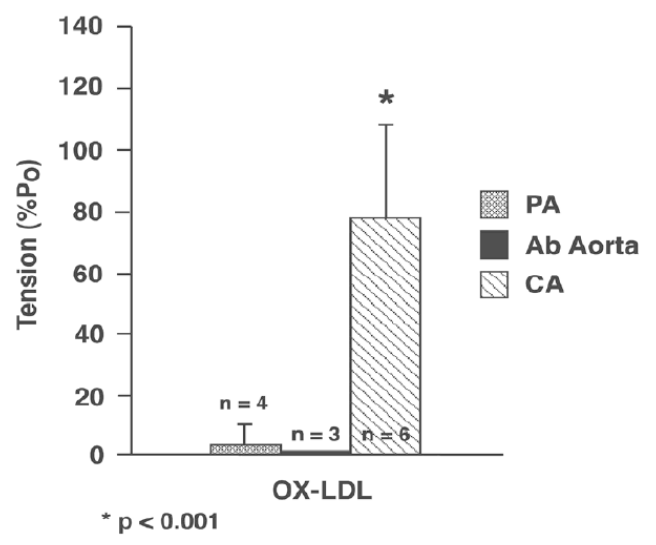

Fig. (4). ZS caudal arterial muscle $(C A ; n=6)$ produced significant active tension in response to $200 \mu \mathrm{g} / \mathrm{ml}$ OX-LDL compared with pulmonary arterial muscle (PA; $n=4 ; \mathrm{p}<0.001)$. Pulmonary arterial muscle and abdominal aorta (Ab Aorta; $n=3)$ produced negligible active tension to OX-LDL ( $\mathrm{p}>0.05)$.

Most antihypertensive medications chelate metals and, therefore, act as antioxidants in addition to their various other mechanisms of action. Nifedipine, nicardipine, propranol, captopril and verapamil have membrane antioxidant activities [22-26]. Captopril scavenges superoxide anions [25]. Nicardipine, nifedipine and verapamil protect against free radical-mediated impaired endothelial cell proliferation [27]. Reports describing the actions of new "third generation" antihypertensive drugs with both $\beta$-adrenergic blocking and vasodilator activity are of particular relevance to the current study. Carvedilol is a drug known to combine $\alpha$ - and $\beta$-blockade with antioxidant properties. When compared with arotinolol, an $\alpha$ - and $\beta$-blocker without antioxidant properties, carvedilol was superior at both improving forearm blood flow and reducing systolic blood pressure [28]. Taken together, these studies suggest that the antioxidant actions of antihypertensive agents may have an important influence in decreasing peripheral resistance and, consequently, lowering blood pressure in hypertensive individuals particularly in disorders such as Type II diabetes in which oxidant load is known to be high. Moreover, the effects of statins on lowering blood pressure might also be explained by the vasoconstrictive effects of oxidized LDL, since statins both lower LDL and exert antioxidant effects [29].
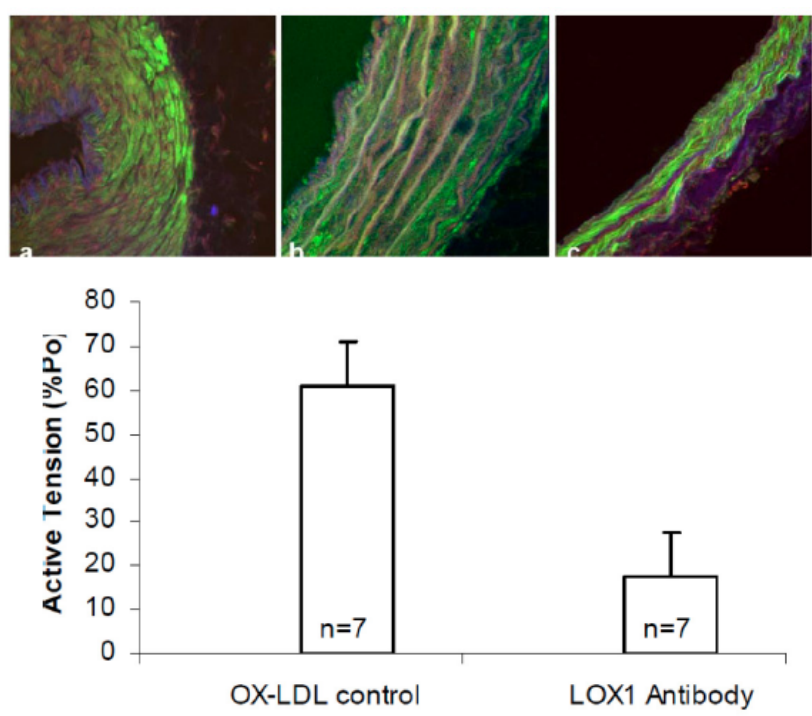

Fig. (5). Upper Panel: Comparison of micrographs (40X) of three different S-D arterial types: a) caudal artery, b) abdominal aorta, c) pulmonary artery. OX-LDL receptors are stained red, with other stains used to establish cell type including phalloidin (green) which stains filamentous actin, and DAPI (blue) which stains cell nuclei. OX-LDL density is greater on caudal arterial muscle than on pulmonary arterial or aortic muscle. Lower Panel: Comparison of OX-LDL induced contractile force for S-D rat caudal arterial muscle in the absence and presence of the LOX1 antibody. Although not quite statistically significant due to high variance and unequal standard deviations, LOX1 Ab appears to have an inhibitory effect on the OX-LDL induced contraction $(\mathrm{p}<0.09)$.

Vascular smooth muscle contraction is regulated primarily by the $\mathrm{Ca}^{2+}$-dependent phosphorylation of the $20 \mathrm{kD}$ regulatory myosin light chain (MLC) $\mathrm{H}_{2} \mathrm{O}_{2}$ induces a slow, sustained contraction in vascular muscle which is independent of calcium and of MLC phosphorylation [2]. Postulated alternative regulatory pathways involving protein kinase $\mathrm{C}$ (PKC) and mitogen activated protein kinase (MAPK) have also been ruled out in the signal transduction of $\mathrm{H}_{2} \mathrm{O}_{2}$-mediated contractions [18]. Less is known about the cellular mechanism involved in mediating contraction in response to another vasoactive oxidant, OX-LDL. Results of the current study show that: 1 . Oxidized LDL is a direct vasoconstrictor with greater efficacy in systemic muscular arteries than in low-pressure pulmonary or in systemic conduit vessels, possibly due to greater density of receptors in the media of muscular arteries. 2. OX-LDL contractions appear to be mediated via LOX1 interaction. 3. OX-LDL induced contraction is slow and sustained and appears to have a calcium-independent component as has been shown for $\mathrm{H}_{2} \mathrm{O}_{2}$ induced contraction. 4. In contrast to $\mathrm{H}_{2} \mathrm{O}_{2}$-induced contractions, OX-LDL contractions are partially mediated by MLCK activity when in the presence of calcium, and 5. 


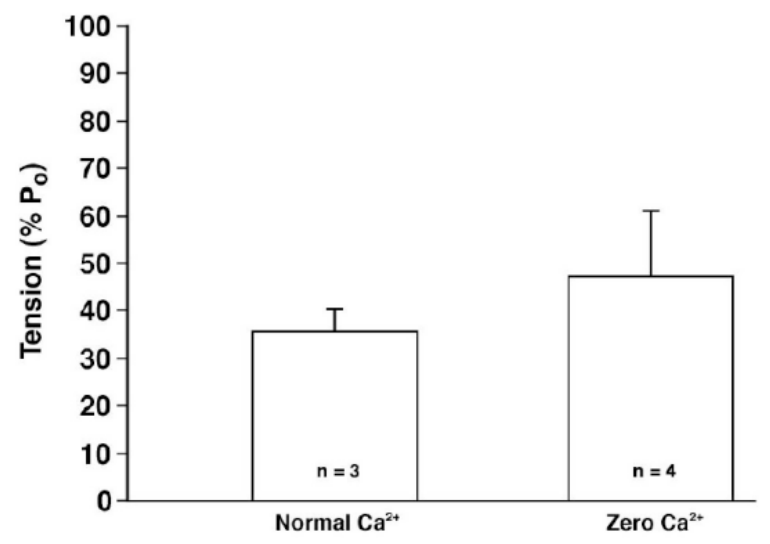

Fig. (6). Upper Panel: Typical isometric Force vs Time tracings for S-D rat caudal arterial muscle strips in response to high $\mathrm{K}^{+}$and to OX-LDL in the presence $(\mathbf{A})$ or absence $(\mathbf{B})$ of calcium. Following an equilibration period at optimal resting tension, the strips were maximally contracted with a supramaximal high $\mathrm{K}^{+}$stimulus. Modified $\mathrm{KHB}$ containing $1.91 \mathrm{mM} \mathrm{Ca}^{2+}$ was used to washout the high potassium solution in the control condition (A) while zero calcium KHB was used for washout in the test protocol (B). In both cases, the muscle relaxed completely after washout of the $\mathrm{KCl}$. Subsequent stimulations with high $\mathrm{K}^{+}$failed to generate a contraction in the muscle preparation in the zero calcium solution. However, addition of OX-LDL resulted in contraction in both the presence and absence of calcium. Lower Panel: Comparison of mean OX-LDL induced contractile force for rat caudal arterial muscle in normal calcium solution and in zero calcium solution. Mean data is normalized as percent of the respective $\mathrm{KCl}$ induced control contractions for comparative purposes. There was no difference in the magnitude of the OX-LDL response regardless of the calcium availability $(\mathrm{p}>0.05)$.

A

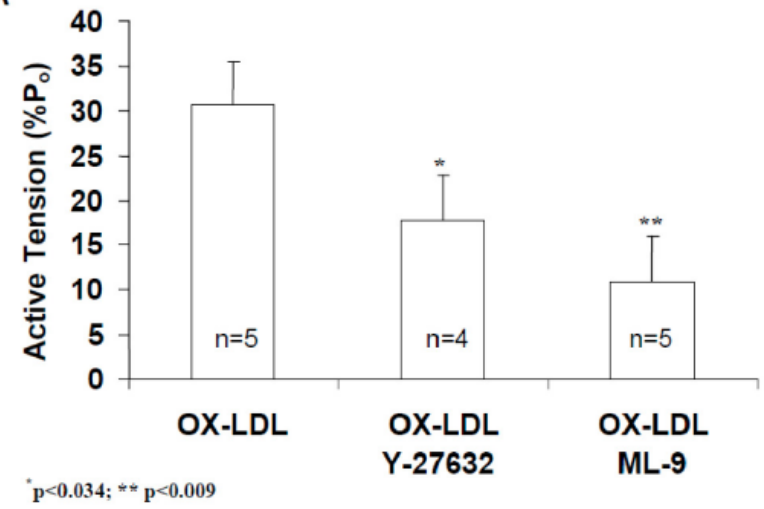

B

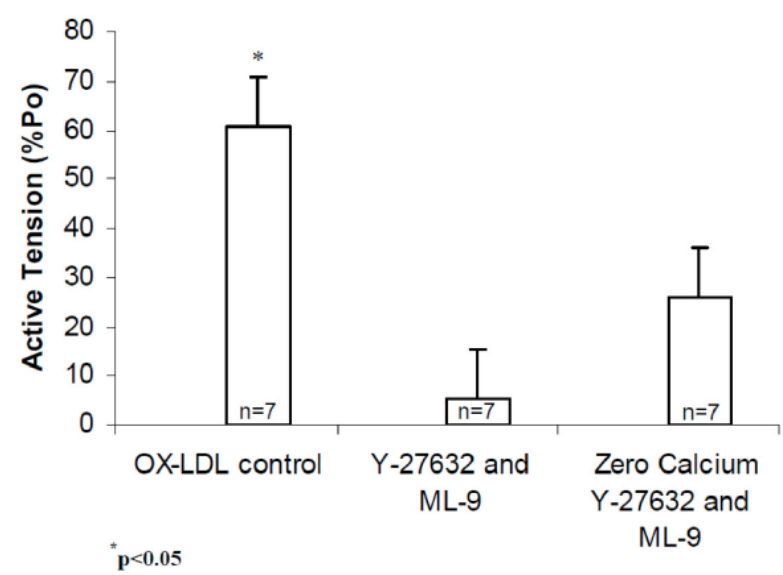

Fig. (7). Panel A: Comparison of OX-LDL induced contractile force for S-D rat caudal arterial muscle in the absence and presence of the Rho kinase inhibitor, Y-27632, or the myosin light chain kinase (MLCK) inhibitor, ML-9. OX-LDL contractions in the presence of Y-27632 or ML-9 were reduced by about $42 \%(\mathrm{p}<0.034)$ and $65 \%(\mathrm{p}<0.009)$, respectively, compared with contractile force in response to OX-LDL alone. MLCK inhibition was about 1.7 times as effective in reducing the contractile response to OXLDL as was Rho kinase inhibition, although neither inhibitor, ML-9 or Y-27632, respectively, abolished the OX-LDL contraction. Panel B: Comparison of the effect of the Rho kinase inhibitor, Y-27632, and the myosin light chain kinase (MLCK) inhibitor, ML-9, used in combination on OX-LDL induced S-D rat caudal arterial muscle contractile force in normal calcium and in zero calcium. The additive effect of the Rho kinase and MLCK inhibitors almost completely blocked the OX-LDL induced contraction $(\mathrm{p}<0.05)$. Interestingly, the combined Y-27632 and ML-9 inhibitory effect was greater in normal calcium than in zero calcium.

Rho kinase activity appears to play a concomitant role in mediating the OX-LDL contraction. The vasoactive oxidants may share an alternate signaling pathway that involves Rho kinase and that is common to this class of agonists but unique from other classes of vasoconstrictor agonists. In this regard, several postulated second messenger systems remain to be explored. Rho may be activated by LOX1 Gq-mediated pathways and result in contraction by changing the MLCK calcium sensitivity [30] through inhibition of $\mathrm{MLC}_{20}$ phosphatase or by direct $\mathrm{MLC}_{20}$ phosphorylation [31]. Alternatively, Rho kinase may stimulate stress fiber formation and cytoskeletal interactions [32] even in the absence of calcium.
Disinhibition of actin-myosin interactions by PAK (p21activated kinase, a Rho family member) phosphorylation of caldesmon is another possible candidate [33]. Other possibilities include direct oxidation of contractile proteins or cytoskeletal elements with reorganization. Understanding the regulatory signals for oxidant-induced vasoconstriction should lead to new and improved anti-hypertensive therapies.

\section{CONFLICT OF INTEREST}

The authors confirm that this article content has no conflicts of interest. 


\section{ACKNOWLEDGEMENTS}

Supported by an American Heart Association: Indiana Affiliate Grant-in-Aid and the 2001 and 2002 M Irené Ferrer Awards for Original Gender-Specific Research made possible by The Partnership for Gender-Specific Medicine at Columbia, Astra-Zeneca and MultiMedia HealthCare/Freedom, LLC. AE Rice was the recipient of an Alpha Omega Alpha Student Research Fellowship and of a Society of Experimental Biology and Medicine Young Investigator Award. GV Potter, WA White and AH Roth were American Physiological Society Frontiers in Physiology Summer Research Teacher Award recipients. NJ Pelaez was a Howard Hughes Medical Institute Fellow.

\section{REFERENCES}

[1] Packer CS, Tang N, Pelaez NJ, Dominguez JH, Eds. Oxidized LDL (OX-LDL) causes endothelium-independent contraction of isolated arterial muscle. Second John C Seidel Memorial Symposium on Smooth Muscle Cells: Structure, Motility and Signaling; 1999.

[2] Pelaez NJ, Braun TR, Paul RJ, Meiss RA, Packer CS. $\mathrm{H}_{2} \mathrm{O}_{2}$ mediates $\mathrm{Ca}^{2+}$ - and $\mathrm{MLC}_{20}$ phosphorylation-independent contraction in intact and permeabilized vascular muscle. Am J Physiol 2000; 279: 185-93.

[3] Karman RJ, Garcia JGN, Hart CM. Endothelial cell monolayer dysfunction caused by oxidized low density lipoprotein: attenuation by oleic acid. Prostaglandins Leukot Essent Fatty Acids 1997; 56: 345-53.

[4] Fruchart, Jean-Charles. Handbook of dyslipidemia and atherosclerosis. Excerpta Medica Publications, Elsevier Science Limited, Paris France, 2003.

[5] Cox DA, Cohen ML. Effects of oxidized low-density lipoprotein on vascular contraction and relaxation: clinical and pharmacological implications in atherosclerosis. Pharmacol Rev 1996; 48: 3-19.

[6] Harrison DG. Endothelial function and oxidant stress. Clin Cardiol 1997; 20(11 Suppl 2): II-11-7.

[7] Schnackenberg CG, Wilcox CS. Two-week administration of tempol attenuates both hypertension and renal excretion of 8-isoprostaglandin F2 alpha. Hypertension 1999; 33(1 Pt 2): 424-8.

[8] Suzuki H, Swei A, Zweifach BW, Schmid-Schoenbein GW. In vivo evidence for microvascular oxidative stress in spontaneously hypertensive rats: hydroethidine microflurography. Hypertension 1995; 25: 1083-9.

[9] Meier B, Radeke HH, Selle S, et al. Human fibroblasts release reactive oxygen species in response to interleukin-1 or tumor necrosis factor-alpha. Biochem J 1989; 263: 539-45.

[10] Guyton KZ, Liu Y, Gorospe M, et al. Activation of mitogenactivated protein kinase by $\mathrm{H}_{2} \mathrm{O}_{2}$. J Biol Chem 1996; 271: 4138-42.

[11] Krieger-Brauer HI, Kather H. Human fat cells possess a plasma membrane-bound $\mathrm{O}_{2}$-generating system that is activated by insulin via a mechanism bypassing the receptor kinase. J Clin Invest 1992; 89: 1006-13.

[12] Rao GN, Runge MS, Alexander RW. Hydrogen peroxide activation of cystolic phospholipase A2 in vascular smooth muscle cells. Biochim Biophys Acta 1995; 1265: 67-72.

[13] Zafari AM, Ushio-Fukai $\mathrm{M}$, Aklers $\mathrm{M}$, et al. Role of $\mathrm{NADH} / \mathrm{NADPH}$ oxidase derived $\mathrm{H}_{2} \mathrm{O}_{2}$ in Angiotensin II-induced vascular hypertrophy. Hypertension 1998; 32: 488-95.

[14] Jameson M, Dai FX, Luescher T, et al. Endothelium-derived contracting factors in resistance arteries of young spontaneously hyper- tensive rats before development of overt hypertension. Hypertension 1993; 21: 280-288.

[15] Laursen JB, Rajagopalan S, Galis Z, et al. Role of superoxide in angiotensin II-induced but not catecholamine-induced hypertension. Circulation 1997; 95: 588-93.

[16] Rhoades RA, Packer CS, Roepke DA, et al. Reactive oxygen species alter contractile properties of pulmonary arterial smooth muscle. Can J Physiol Pharmacol 1990; 68:1581-9.

[17] Sheehan DW, Giese EC, Gugino SF, Russell JA. Characteristics and mechanisms of $\mathrm{H}_{2} \mathrm{O}_{2}$-induced contractions of pulmonary arteries. Am J Physiol 1993; 264: 1542-7.

[18] Pelaez NJ, Osterhaus SL, Mak AS, et al. MAPK and PKC activity are not required for $\mathrm{H}_{2} \mathrm{O}_{2}$-induced arterial muscle contraction. Am J Physiol Heart Circ Physiol 2000; 279(3): H1 194-200.

[19] Dekhuijzen PNR, Aben KKH, Dekker I, et al. Increased exhalation of hydrogen peroxide in patients with stable and unstable chronic obstructive pulmonary disease. Am J Respir Crit Care Med 1996; 154: 813-6.

[20] Hyslop PA, Zhang Z, Pearson DV, Phebus LA. Measurement of striatal $\mathrm{H}_{2} \mathrm{O}_{2}$ by microdialysis following global forebrain ischemia and reperfusion in the rat: correlation with the cytotoxic potential of $\mathrm{H}_{2} \mathrm{O}_{2}$ in vitro. Brain Res 1995; 671(2): 181-6.

[21] Jobsis Q, Raatgeep HC, Hermans PWM, deJongste JC. Hydrogen peroxide in exhaled air is increased in stable asthmatic children. Eur Respir J 1997; 10: 519-21.

[22] Chopra M, Beswick H, Clapperton M, et al. Antioxidant effects of angiotensin-converting enzyme (ACE) inhibitors: free radical and oxidant scavenging are sulfhydryl dependent, but lipid peroxidation is inhibited by both sulfhydryl- and nonsulfhydryl-containing ACE inhibitors. J Cardiovasc Pharmacol 1992; 19: 330-40.

[23] Weglicki WB, Mak IT. Antioxidant drug mechanisms; transition metal-binding and vasodilation. Mol Cell Biochem 1992; 118: 105111.

[24] Mak IT, Weglicki WB. Comparative antioxidant activities of propranolol, nifedipine, verapamil, and diltiazem against sarcolemmal membrane lipid peroxidation. Circ Res 1990; 66: 1449-52.

[25] Weglicki WB, Mak IT. Mechanisms of cardiovascular drugs as antioxidants. J Mol Cell Cardiol 1990; 22: 1199-208.

[26] Weglicki WB, Mak IT. Antioxidant activity of calcium channel blocking drugs. Methods Enzymol 1994; 234: 620-30.

[27] Mak IT, Boehme P, Weglicki WB. Protective effects of calcium channel blockers against free radical-impaired endothelial cell proliferation. Biochem Pharmacol 1995; 50(9): 1531-4.

[28] Watanabe H, Kakihana M, Ohtsuska S, Sugishita Y. Preventive effects of carvedilol on nitrate tolerance- a randomized, doubleblind, placebo-controlled comparative study between carvedilol and arotinolol. Hypertension 1998; 32(5): 1201-6.

[29] Briasoulis A, Agarwal V, Valachis A, Messerli F. Antihypertensive effects of statins: a meta-analysis of prospective controlled studies. J Clin Hypertens 2013; 15: 310-20.

[30] Sakurada S, Takuwa N, Sugimoto N, et al. $\mathrm{Ca}^{2+}$-dependent activation of Rho and Rho kinase in membrane depolarization induced and receptor stimulation-induced vascular smooth muscle contraction. Circ Res 2003; 93: 548-56.

[31] Ito K, Shimomura E, Iwanaga T, et al. Essential role of Rho kinase in the $\mathrm{Ca}^{2+}$ sensitization of prostaglandin $\mathrm{F} 2 \alpha$-induced contraction of rabbit aortae. J Physiol 2000; 546(Pt 3): 823-36.

[32] Turner CE. Paxillin and focal adhesion signalling. Nat Cell Biol 2000; 2: 231-6.

[33] Foster DB, Shen LH, Kelly J, et al. Phosphorylation of caldesmon by 21 -activated kinase, implications for the $\mathrm{Ca}^{2+}$ sensitivity of smooth muscle contraction. J Biol Chem 2000; 275: 1959-65.

\begin{tabular}{lcc}
\hline Received: April 24, 2014 & Revised: April 25, 2014 & Accepted: April 26, 2014 \\
(C) Packer et al.; Licensee Bentham Open. &
\end{tabular}

This is an open access article licensed under the terms of the Creative Commons Attribution Non-Commercial License (http://creativecommons.org/licenses/by-nc/3.0/) which permits unrestricted, non-commercial use, distribution and reproduction in any medium, provided the work is properly cited. 